\title{
Water Stable Isotope Composition of Precipitations at Two Stations in Antananarivo-Madagascar: A Comparative Study
}

\author{
Voahirana Ramaroson ${ }^{1,2}$, Joel Rajaobelison ${ }^{1,2}$, Lahimamy P. Fareze ${ }^{1}$, Falintsoa A. Razafitsalama ${ }^{1}$, \\ Mamiseheno Rasolofonirina ${ }^{2} \&$ Christian U. Rakotomalala ${ }^{1}$ \\ ${ }^{1}$ Institut National des Sciences et Techniques Nucléaires, Madagascar \\ ${ }^{2}$ Department of Physics and Applications, University of Antananarivo, Madagascar \\ Correspondence: Voahirana Ramaroson, Institut National des Sciences et Techniques Nucléaires, P.O. Box 3907 \\ 101 Antananarivo, Madagascar. Tel: 261-320-214-382. E-mail: vramaroson@yahoo.com
}

Received: November 27, 2021

Accepted: January 19, 2022 Online Published: January 26, 2022

doi:10.5539/esr.v11n1p1

URL: https://doi.org/10.5539/esr.v11n1p1

\begin{abstract}
In the "Global Network of Isotopes in Precipitation" database, Antananarivo has two distinct datasets from two stations. Thirty-four years separate the two datasets. This study aims on the one hand to depict the variations of the water stable isotopes composition of precipitations from the two stations and understand their origins, mainly in relation to meteorological factors. On the other hand, the Antananarivo data are compared with regional and international data to identify other sources of isotope composition variability in precipitation. Isotope records showed that after thirty-four-year gap, summer and winter (the two main seasons) precipitations are more enriched in heavy isotopes. The precipitation amount fluctuation would mostly contribute to this temporal variation. Opposite to summer and winter precipitations, inter-season rainfalls have similar isotope values after thirty-four years. The two stations are geographically close and the spatial aspect is therefore negligible since there are no latitude nor altitude effects on the isotope composition of precipitations. Regarding the second order parameter d-excess, the monthly mean values from both stations are higher than $10^{\circ} \%$ and could indicate moisture recycling. The comparison with regional/international data showed that the isotope variability in precipitation is primarily due to precipitation amount effect, different moisture source, the stations distance from it and the change of meteorological factors along the moisture trajectory.
\end{abstract}

Keywords: Antananarivo, international, isotope, moisture source, precipitation amount, regional, temporal variation

\section{Introduction}

Isotope fractionation occurring during water phase change along the water cycle results in characteristic isotopic fingerprint for condensed and evaporated waters. Ratios of heavy over light isotopes of oxygen and hydrogen in water, in particular air mass, are temperature-dependent during condensation and vary with relative humidity during evaporation as results of equilibrium and kinetic fractionation (Clark \& Fritz, 1997). The stable isotopes ratios of air moisture in an air mass reflect the origin of the air mass, while the ratios in the precipitation emerging from the air mass are both specific to the air mass origin and the conditions under which condensation occurs (Kumar, Tiwari, Verma, \& Gupta, 2018). Stable isotopes content in precipitation have been used in various hydrological studies and have proven to be powerful tools in understanding hydrogeological patterns. Changes in the isotope composition of precipitation have been observed as results of geographical, climatic and temporal variations. Among the different effects is more depleted precipitation in heavy isotopes with increasing altitude and towards the poles, with temperature being the major parameter determining the stable isotopic composition of precipitation (Dansgaard, 1964; Mazor, 2004). In Costa Rica, a slope of $-1.6^{0} \%{ }_{00} \delta^{18} \mathrm{O}$ per $100 \mathrm{~mm}$ of rain with $\mathrm{r}^{2}=0.57$ corresponding to a temperature effect of $0.37 \%{ }_{00} \delta^{18} \mathrm{O} /{ }^{\circ} \mathrm{C}$ was determined, and $-2^{0} \%{ }_{00} \delta^{18} \mathrm{O}$ per $\mathrm{km}$ of elevation (Sánchez-Murillo et al., 2013). In the Northeastern Caribbean, there was significant difference of the isotope composition of rainfall between months, but little difference between years as result of intermonth rainfall fluctuation (Govender, Cuevas, Sternberg, \& Jury, 2013). Surface air temperature, relative humidity, and precipitation amount moderately and strongly correlate with the isotopic composition of precipitation from individual events in Southwest Idaho (Tappa, Kohn, McNamara, \& Flores, 2016). 
The long time running Global Network of Isotopes in Precipitation (GNIP), jointly monitored by the International Atomic Energy Agency (IAEA) and the World Meteorological Organization (WMO) allows scientists all over the world to access valuable water stable isotopes $\left(\delta^{18} \mathrm{O}\right.$ and $\left.\delta^{2} \mathrm{H}\right)$ and tritium $\left({ }^{3} \mathrm{H}\right)$ data in precipitation for water resources and atmospheric studies. Madagascar first participated in the GNIP program in 1961, with one station in the northern area of Antananarivo, the capital city. This first involvement ended in 1975 and the country has been participating again in the program since 2009, with a new station, located in the Central Southeast of Antananarivo.

This work deals with a comparative study of the stable isotope variations $\left(\delta^{18} \mathrm{O}, \delta^{2} \mathrm{H}\right.$, and deuterium excess $)$ in precipitation from two stations in Antananarivo, while focusing on the temporal effect taking into account that there is a time gap of 34 years between the two stations archived datasets. The combined Antananarivo dataset is also compared with isotope records from regional and international GNIP stations, mainly for spatial variation purposes.

\section{Description of the Study Area}

\subsection{Geographical Settings}

Madagascar is an island, located in the Indian Ocean, at latitude $18.7669^{\circ} \mathrm{S}$ and longitude $46.8691^{\circ} \mathrm{E}$. The island can be characterized by narrow coastal plains, high plateau and mountainous areas in the central part and can be divided into five geographical regions: the east coast, the Tsaratanana Massif, the central highlands, the west coast, and the southwest. The central highlands, which range from 800 to 1,800 meters in altitude, contain a wide variety of topographies: rounded and eroded hills, massive granite outcroppings, extinct volcanoes, eroded peneplains, and alluvial plains and marshes, which have been converted into irrigated rice fields (Metz, 1995). Antananarivo, the national capital, is located in the northern portion of the central highlands at 1,468 meters above sea level (Wachsberger, 2009). The two GNIP stations are located in Antananarivo (Analamanga region), which is part of the central highlands (Figure 1a). The first older station, named Ivato, operated from 1961 to 1975 , at a latitude of $18.90^{\circ} \mathrm{S}$ and a longitude of $47.53^{\circ} \mathrm{E}$, at $1300 \mathrm{~m}$ a.s.l. The second more recent station, named Ankatso, has been operating since 2009 , and is located at latitude $18.91^{\circ} \mathrm{S}$ and longitude $47.56^{\circ} \mathrm{E}$, at $1295 \mathrm{~m}$ a.s.l. The two stations are about $15 \mathrm{~km}$ distant from each other.

\subsection{Climate Features}

According to the Köpplen Climate classification, the Central highland of Madagascar climate is classified as that of subtropical highland $(\mathrm{Cwb})$. This type of climate is characterized by warm to hot summers, by air temperatures which usually do not go below freezing and by little rainfalls during winters (Roth, 2007; Kottek, Grieser, Beck, Rudolf, \& Rubel, 2006). Because of its relatively high altitude, Antananarivo experiences a temperate climate (Peel, Finlayson, \& McMahon, 2007) with two prevailing seasons: hot and rainy, from November to March called summer, on the one hand, and on the other hand cool and dry from May to September, called winter. There are brief interseason months, April (Spring) and October (Autumn). The average winter temperature rarely drops below $10^{\circ} \mathrm{C}$, and the summer temperature rarely exceeds $25^{\circ} \mathrm{C}$ (T. Rambinintsoa, Rakoto, F. Rambinintsoa, Raveloalison, \& Andrianaivo, 2019). The climate is mainly influenced by the southeastern trade winds in winter and tropical cyclones forming remotely in summer in the Indian Ocean (Jury, 2003). The summer rainfall is mostly occurring through convective activity and thunderstorms linked to the Inter-Tropical Convergence Zone (ITCZ), which lies across the northern parts of Madagascar during the summer months of the year (Tadross, Randriamarolaza, Rabefitia, \& Zheng, 2008). Besides, as the northwest monsoon winds blow across the central highland plateau, they bring rain in the northwest coast of Madagascar and in the central highland plateau in summer (Covell, Kent, Southall, Dresch, \& Deschamps, 2019). The southeastern trade winds originate in the Indian Ocean anticyclone, a center of high atmospheric pressure that seasonally changes its position over the ocean (Metz, 1995) and is responsible for the dry winter. On average, Antananarivo receives $1441 \mathrm{~mm}$ of precipitation annually, with a maximum temperature of $26.74^{\circ} \mathrm{C}$ and minimum temperature of $14.01^{\circ} \mathrm{C}$, giving a mean annual temperature of $20.37^{\circ} \mathrm{C}$ (based on data for 114 years from the World Bank Group, Climate Change Knowledge Portal, 2020). Historical climate records in Madagascar indicate an increase of daily temperature across all seasons, pronounced increases in daily maximum temperatures during the dry season and longer periods of drought in the central part of the country (United States Agency for International Development [USAID], 2016). The mean monthly precipitation and temperature data from the GNIP database illustrate the climate features and the temporal climate variation over the time gap of the two stations operationality (Figure 1b). Figure $1 \mathrm{~b}$ shows a clear increase of the monthly temperature mean within a period of 34 years with a temperature gradient of $0.66^{\circ} \mathrm{C}$ in July and a higher gradient of $1.98^{\circ} \mathrm{C}$ in December. Generally, the monthly rainfall mean indicates a steady decrease of rains during both summer and winter after 34 years. 

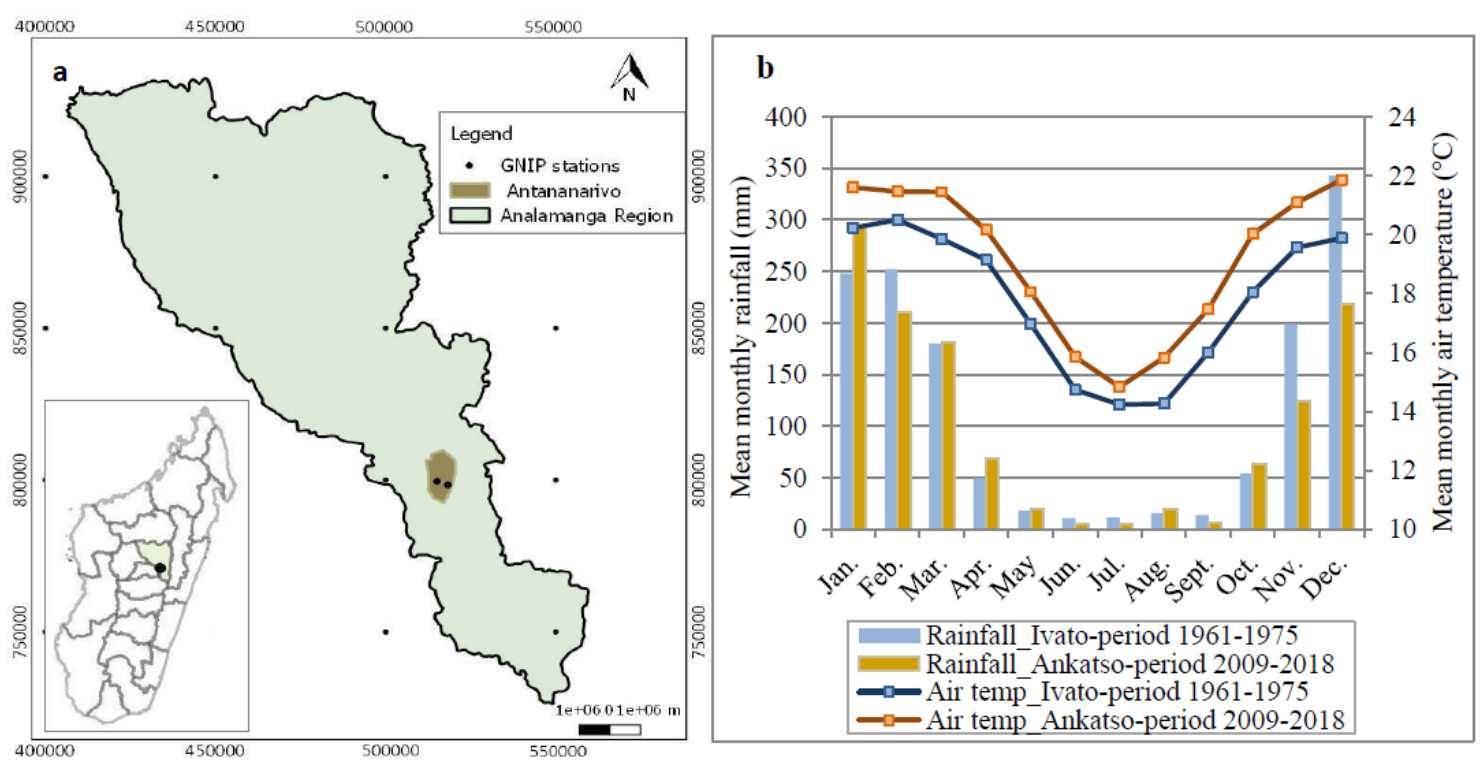

Figure 1. (a) Geographical locations of the two GNIP stations. (b) Mean monthly rainfall and temperature data from the two GNIP stations

Ivato period: [1961-1975]. Ankatso period: [2009-2018]. Source GNIP database

\section{Methodology}

Water stable isotope is defined as the stable isotopes of the atoms of hydrogen and oxygen, the two atoms composing the water molecule. Hydrogen has three isotopes: protium ${ }^{1} \mathrm{H}$ and deuterium ${ }^{2} \mathrm{H}$, which are stable; and tritium ${ }^{3} \mathrm{H}$, which is radioactive. Oxygen has also three isotopes: ${ }^{16} \mathrm{O},{ }^{17} \mathrm{O}$ and ${ }^{18} \mathrm{O}$, which are all stable. In the science of Isotope hydrology, the water stable isotopes of interest are deuterium ${ }^{2} \mathrm{H}$ and ${ }^{18} \mathrm{O}$.

Delta (symbol $\delta$ ) is used to express the relative difference of the isotope ratio (Tyler, 2011) of an element and that of a standard, as given by equation (1), and according to the new reporting for stable isotopes (Brand, 2011). The isotopic ratio is the ratio between the (heavy and rare) isotope and the (light and abundant) isotope. In many natural systems, the range of this ratio is in the third to fifth decimal place, hence the invention of the delta notation to express the isotopic ratio variability in a convenient way (Pinti, 2011).

$$
\delta=\frac{R_{\text {sample }}-R_{\text {standard }}}{R_{\text {standard }}}
$$

where $\mathrm{R}$ is the isotope ratio. $\delta$ is expressed in per mil (part per thousand, ${ }^{0} \% 0$ )

Thus, for the water stable isotopes ${ }^{2} \mathrm{H}$ and ${ }^{18} \mathrm{O}, \quad \delta$ is expressed respectively by the equations (2) and (3)

$$
\begin{gathered}
\delta^{2} \mathrm{H}=\frac{\left(\frac{2_{H}}{1_{H}}\right) \text { sample }-\left(\frac{2_{H}}{1_{H}}\right) \text { VSMOW }}{\left(\frac{2_{H}}{1_{H}}\right) \text { VSMOW }} \\
\delta^{18} \mathrm{O}=\frac{\left(\frac{18 O}{16_{O}}\right) \text { sample }-\left(\frac{18 O}{16_{O}}\right) \text { VSMOW }}{\left(\frac{18_{O}}{16_{H}}\right) \text { VSMOW }}
\end{gathered}
$$

$\delta^{2} \mathrm{H}$ and $\delta^{18} \mathrm{O}$ define the water stable isotope composition in any water sample type. The international standard VSMOW (Vienna Standard Mean Ocean Water) is the standard used for the $\delta^{2} \mathrm{H}$ and $\delta^{18} \mathrm{O}$ measurements, which are performed using mass spectrometry and later by laser absorption spectroscopy. With the latter type of equipment, $1-\sigma$ measurement precision below $0.5 \%$ for $\delta^{2} \mathrm{H}$ and $0.1 \%$ for $\delta^{18} \mathrm{O}$ were reported by the manufacturer (Penna et al., 2012). With mass spectrometry, the measurement accuracy is $\pm 0.7 \%$ and $\pm 0.05 \%$ o for $\delta^{2} \mathrm{H}$ and $\delta^{18} \mathrm{O}$ measurements, respectively (Penna et al., 2012).

Specifically for precipitation, the water stable isotope composition plots along the linear equation $\delta^{2} \mathrm{H}=8^{*} \delta^{18} \mathrm{O}$ 
+10 (Craig, 1961) on a global scale. The equation is known as the Global Meteoric Water Line (GMWL) for non-evaporated precipitation and indicates the global distribution of precipitation. Because of different environment and climatic conditions in different places in the world, the water stable isotope composition in precipitation in a specific site shifts from the GMWL (Singh, 2017). The new line is called Local Meteoric Water Line (LMWL), deriving from the stable isotopes $\left(\delta^{2} \mathrm{H}\right.$ and $\left.\delta^{18} \mathrm{O}\right)$ in precipitation pertaining to a local site.

Apart from $\delta^{2} \mathrm{H}$ and $\delta^{18} \mathrm{O}$, a second-degree parameter $d$, called deuterium excess (d-excess) is given by the equation (4).

$$
d=\delta^{2} \mathrm{H}-8^{*} \delta^{18} \mathrm{O}
$$

The knowledge of the water stable isotope composition in precipitation, that is its $\delta^{2} \mathrm{H}$ and $\delta^{18} \mathrm{O}$ and additionally the d-excess helps understand the meteorological processes, the water vapor source region and the circulation patterns (J. Wang, Li, Y. Wang, Zhang, \& Xiao, 2021). The GNIP network, composed of hundreds of stations worldwide allowed understanding the spatial and temporal variability of the isotope composition of precipitation. These stations are located in different parts of the world and are characterized by different geographical positions, different climate features and different precipitation patterns. The isotope composition of precipitation therefore depends on temperature, precipitation amount, altitude, and distance from the source moisture (Stern \& Blisniuk, 2002). The d-excess reflects the precipitation formation from the geographical environment and the climatic conditions (Wang et al., 2021).

To study the water stable isotope composition in precipitations at the two stations in Antananarivo to determine any spatial and temporal variation of the $\delta^{2} \mathrm{H}$ and $\delta^{18} \mathrm{O}$ and explain the sources of the disparity, the data used are from the GNIP database. For the Ivato dataset (period 1961-1975), the analyses were performed by the University of Copenhagen. For the Ankatso dataset (period 2009-2018), the station was operated by the "Institut National des Sciences et Techniques Nucleaires"Isotope Hydrology department. For the latter station, the rainfall samples were collected according to the IAEA protocol (International Atomic Energy Agency [IAEA], 2014). The sampling device is NOAA-National Weather Service model, with a NOVA LYNX model as precipitation collector. The precipitation amount is recorded manually with a rain gauge. The sampling device is installed on a flat unruffled terrain, and protected inside a square concrete wall, where the funnel is about $35 \mathrm{~cm}$ above the ground. The rain sample is transferred into an intermediate accumulation vessel after each rain event, for daylight rains. As for night time rains, the sample is collected early in the morning the following day. The monthly vessel is labelled with the month and year of sampling and preserved in an appropriate refrigerator, waiting for the shipment to the IAEA Isotope Hydrology Laboratory for analysis. The shipment is planned and organized by the IAEA, within the first quarter following the year of sampling. For shipments, the monthly accumulated samples are transferred into $30 \mathrm{~mL}$ dark glass bottles, provided by the IAEA. Monthly meteorological data, including air temperature, precipitation amount and relative humidity are provided in the shipment package. Analysis is performed on the monthly accumulated samples to have the $\delta^{2} \mathrm{H}$ and $\delta^{18} \mathrm{O}$ in precipitation. The GNIP database therefore records monthly isotope data.

\section{Results and Discussion}

\subsection{Comparison of Data from the Two Stations}

\subsubsection{Water Stable Isotopes ${ }^{18} \mathrm{O}$ and ${ }^{2} \mathrm{H}$}

The two stations have approximately the same sample size, 66 and 65 for Ivato and Ankatso respectively. The latter station has however fewer isotope records for the dry months due to dryness. Reduction in winter and spring rainfall has been detected over time in most parts of Madagascar (World Bank Group, 2011). In the central region, where the study areas are located, rainfalls are on a steady decline accompanied by dry spells (World Bank Group, 2011).

To compare the two datasets, the classical $\delta^{2} \mathrm{H}$ vs $\delta^{18} \mathrm{O}$ plot helps decipher the dissimilarity between the two datasets one on the one hand and with respect to the GMWL on the other hand.

The stable isotope composition of precipitation from the two stations both plots above the Global Meteoric Water Line-GMWL (Figure 2), which indicates the same hydroclimatic features (Ren, Yao, \& Xie, 2016) in Antananarivo over 34 years. By omitting the most depleted precipitation (having the most negative delta value) recorded for Ivato, the two datasets have approximately the same isotope range (Figure 2). Generally, both datasets overlap quite well on the isotope composition graph (Figure 2). This is revealed particularly by the slope values of the regression lines, which are slightly different for the two stations: $\delta^{2} \mathrm{H}=8.06 \delta^{18} \mathrm{O}+14.00$ for Ivato and $\delta^{2} \mathrm{H}=8.40 \delta^{18} \mathrm{O}+16.69$ for Ankatso (Figure 2). Nevertheless, the slope values for both stations fall within $(8 \pm 0.5)$ for most of LMWLs (Kendall \& McDonnell, 1998). The variation of the equilibrium fractionation ratio 
of $\delta^{2} \mathrm{H}$ to $\delta^{18} \mathrm{O}$ at different temperatures (Putman, \& Bowen, 2019) would explain the minor difference between the two stations' slopes since the value of 8 reflects equilibrium fractionation.

With regard to the intercept, Ankatso has higher intercept than Ivato and both stations have noticeably higher values than the GMWL. The GMWL intercept value of $10 \%$ results from average equilibrium and kinetic fractionation during evaporation from the ocean with a global evaporation-weighted mean relative humidity of $85 \%$ (Clark \& Fritz, 1997). Hence, variation of the relative humidity would elucidate the different intercept values for the two stations. With respect to GMWL, apart from different environment and climatic conditions, mixing of oceanic moisture with terrestrial moisture from evapotranspiration is also a contributing factor that modifies meteoric water lines (Kendall \& Coplen, 2001).

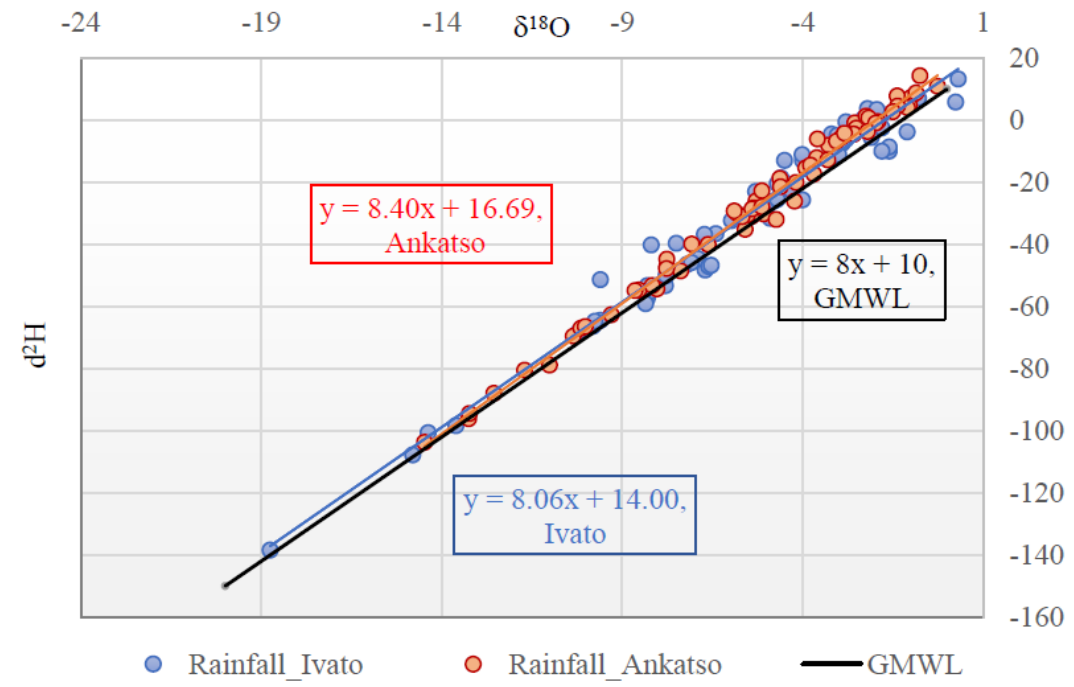

Figure 2. Stable isotope composition of rainfall collected from the two stations

Figure 3 shows the monthly mean $\delta^{18} \mathrm{O}$ over the data collection period of each station. It shows that precipitations are more enriched (less negative delta values) over the time period of 34 years in January, February, November, and December on the one hand; and in June, July and September on the other hand. These are summer and winter months respectively, the main seasons in the Island. Enriched precipitation indicates the occurrence of evaporation. The latter process takes place through small rain events (Hughes \& Crawford, 2012) or in the rainfall collector and is driven by higher air temperature. In fact, there has been an obvious rise of the mean monthly air temperature from [1961-1975] to [2009-2018] (Figure 1b) and the precipitation evaporation-condensation temperatures are the main factors controlling the isotope composition of precipitation (Kendall \& McDonnell, 1998). The plot of the monthly mean $\delta^{18} \mathrm{O}$ also indicates that despite the increase of the stable isotope composition of precipitation within 34 years, the two curves have the same trend (Figure 3). The winter precipitations are more enriched than the summer ones. Summer is characterized by heavy rains, which are more depleted in heavy isotopes than light winter rains (known as amount effect). Opposite to the variation of the isotope composition during the main season months, $\delta^{18} \mathrm{O}$ from the two stations overlaps in March-April and in October (Figure 3). The latter months are interseason months. Figure 1b shows that during these inter-season months, the air temperature increased as well over 34 years, whereas the precipitation amount remained almost constant. This would suggest that precipitation amount fluctuation during the main season months plays a major role in the isotopic composition variation of precipitation for these months. During the inter-season months, the approximate mean monthly $\delta^{18} \mathrm{O}$ data from the two stations suggest that there is no variability over 34 years in the air mass origin and in the conditions under which condensation occurs (Kumar et al., 2018).

The temporal variation of the isotope composition of the precipitation in Antananarivo during the main seasons would result from climate variability. In summer, the climate is governed by tropical cyclones forming far out in the Indian Ocean (Jury, 2003). The occurrences of events such as tropical cyclones affect the stable isotope composition of precipitations. Apart from Australia, Madagascar is the most commonly affected by tropical cyclones in the Southern Hemisphere (Weinkle, Maue, \& Plielke, 2012). The frequency of cyclones has decreased over time in the South West Indian Ocean (Mavume, Rydberg, Rouault, \& Lutjeharms, 2009) and is 
projected to still decrease by 2100 (World Bank Group, 2011). Tropical cyclone rains have lower stable isotope ratios (Lawrence, \& Gedzelman, 1996) probably due to the high, thick clouds, the large precipitation region and the precipitation longevity (Lawrence, Gedzelman, Zhang, \& Arnold, 1998). Such stable isotope ratios decrease has been observed during typhoon in Japan (Fudeyasu et al., 2008), tropical cyclone in the Philippines (Jackisch et al., 2020) and in Oman (Müller, Friesen, Weise, Al Abri, Bait Said, \& Michelsen, 2020). The period [1961-1975] (Ivato station) has higher frequency of highly depleted precipitation than the period [2009-2018] (Ankatso station), which would have originated from tropical cyclone. Besides, as the summer rainfall is also mostly occurring through convective activity, the increase of the air temperature over 34 years could explain that the precipitations are more enriched by evaporation. Therefore, different meteorological parameters, such as surface air temperature, precipitation quantities, and relative humidity due to the climate change could explain the variation of the precipitation isotopic composition from the two stations (Wu, Zhang, Xiaoyan, Li, \& Huang, 2015).

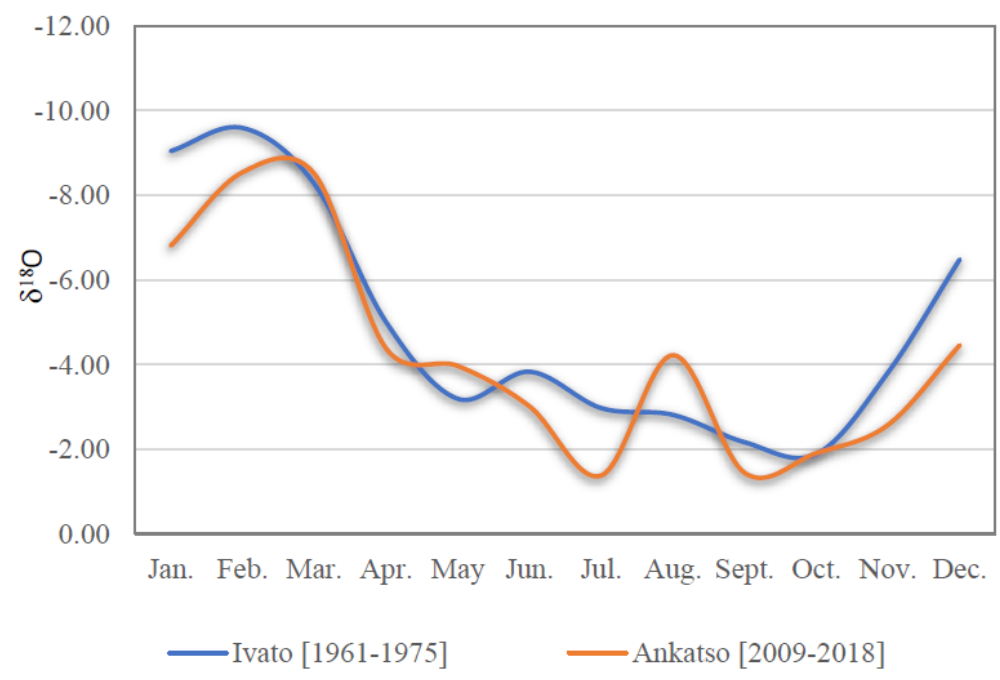

Figure 3. Monthly mean $\delta^{18} \mathrm{O}$ over each period of the two stations

Regarding the spatial effect, the difference of geographic coordinates between the two stations is too small for latitude $\left(\Delta^{18} \mathrm{O}=-0.6 \%\right.$ o $/$ degree of latitude) and altitude effects $\left(\Delta^{18} \mathrm{O}=-0.2\right.$ to $-0.6 \%$ Meijer, 2001) to occur and change the stable isotope contents in the precipitations.

\subsubsection{Deuterium Excess}

For each station, d-excess was calculated using $\delta^{2} \mathrm{H}-8 * \delta^{18} \mathrm{O}$ (equation 4) and the monthly mean over each period was computed. For both stations, the precipitations have monthly mean d-excess values higher than the GMWL $10 \%$. For Ivato, the minimum value is $10.77 \%$ and the maximum value is $17.50 \%$. For Ankatso, the minimum value is $12.48 \%$ and the maximum value is $20.87 \%$. Higher $d$ values $(>10 \%$ ) may indicate additional source of moisture, or moisture recycling (Putman \& Bowen, 2019). The higher $d$ values are characteristics of Indian Ocean d-values in tropical and sub-tropical regions, where oceanic source areas are of high evaporation flux and of smooth wind regime (Froehlich, Gibson, \& Aggarwal, 2002). Deuterium-excess in precipitation increases in response to enhanced moisture recycling as a result of increased evaporate content (Froehlich et al., 2002). Frontal precipitations with moisture sources from the Indian Ocean usually have deuterium excess values between $15 \%$ and $25 \%$ depending on the moisture source direction, whereas the precipitations having inland moisture sources have deuterium excess between $10 \%$ and $25 \%$ (Guan et al., 2013). The $d$ parameter variation depends on several factors, including relative humidity, sea surface temperature, wind speed, moisture source, and moisture source direction. The primary influences on precipitation $d$ local scale variability are the seasonal and spatial variations of moisture sources, which can be large (Sodemann, Schwierz, \& Wernli, 2008). The graph of the monthly mean d-excess values over each period (Figure 4) indicates approximately similar shape of the two curves, except the fluctuation between August and September for Ankatso. The values for these months are not representative of the actual mean value because only few data were available. For August, only one $d$ value is accessible for the entire period 2009-2018, referring to the only August 2015 rainfall at disposal. These atypical values can explain the oscillation of the Ankatso curve within these months. While disregarding the latter portion of the curve, Ankatso has noticeable higher values than Ivato, 
except for November and December (Figure 4), thus an increase of $d$ over 34 years. A much higher evaporation flux of the oceanic source areas as result of increasing air temperature over 34 years partly contributed to the d-excess rise. Figure 4 also highlights lower mean d-excess values during summer (November-March) than during winter (June and July) for both stations, reflecting seasonal variation of the d parameter (Yabusaki, Tase, $\&$ Tsujimora, 2006).

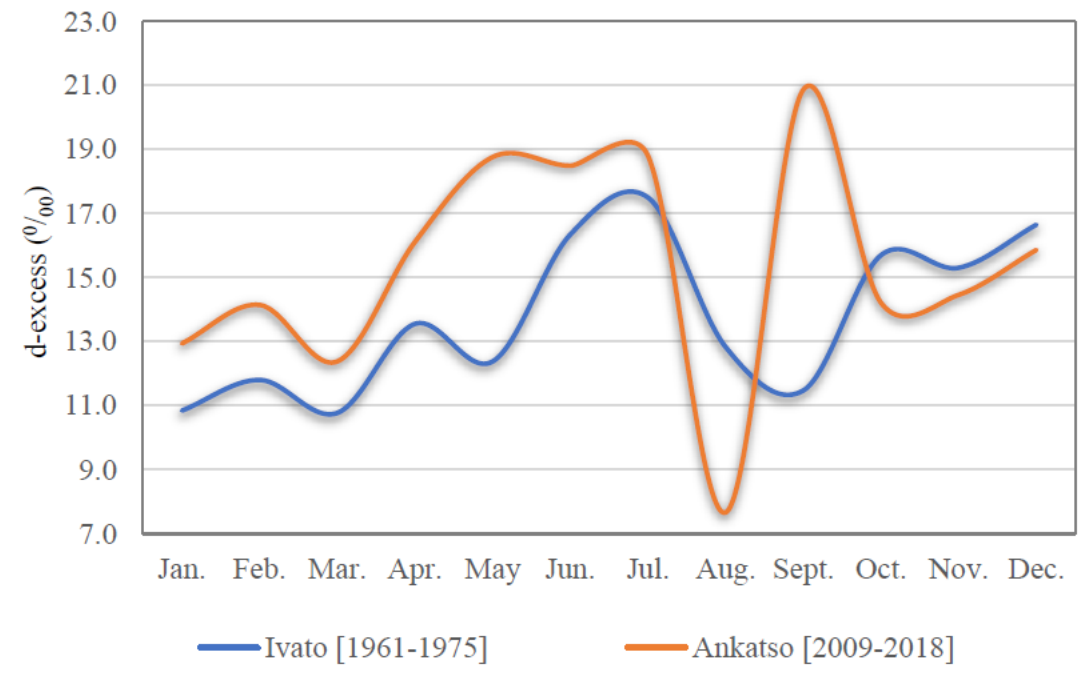

Figure 4. Monthly mean d-excess over each period of the two stations

In Antananarivo, the summer rainfall (November-March) is from convective activity linked to the Inter-Tropical Convergence Zone (ITCZ) and tropical cyclones from orographic rainfall. ITCZ has a large-scale fluctuation and climatology study of monthly precipitation recorded from 1951 to 2003 features high variability during the summer (Nov-Apr) but is less volatile in winter (May-Oct) (Arivelo \& Lin, 2016).

For Ankatso, the seasonal variation of the $d$ parameter is unambiguous with a clear difference of the $d$ parameters between the two main seasons. This is not perceived for Ivato, as there is significant difference of the $d$ parameters within each season. The $d$ parameter values are higher for the summer months of November and December than for the summer months of January to March. The time period of Ivato precipitations lies within the [1951-2003] interval and the variation within the season may be linked to different physical processes among the precipitation events (Guan, Zhang, Skrzypek, Sun, \& Xu, 2013). This can also elucidate the higher $d$ values of November and December precipitations for Ivato, while it is lower for all the other months as compared to Ankatso.

\subsection{Comparison of Antananarivo Data with Regional and International Data}

The two stations in Antananarivo are geographically close. The differences of latitude and altitude are smaller than the step-size for latitude and altitude gradient, implying the absence of effects on the isotopic composition of precipitation. To decipher this type of disparity, the isotope data from the Antananarivo stations are compared to isotope data at regional and international scales from stations located in cities having the same climate features as Antananarivo. Among the cities classified as Cwb climate type in Africa; Addis Ababa- Ethiopia, Harare-Zimbabwe and Pretoria- South Africa have stations within the GNIP network. For these stations, the available data lie within the Antananarivo data period. Moreover, the isotope analyses were performed at least by the same laboratory for both these stations and the Antananarivo stations. From the other continents, Salta-Argentina and Kunming-China, also of Cwb climate type, have available GNIP data. For these two last stations, the GNIP data collection period is outside that of Antananarivo, but helps also understand more the temporal apart from the spatial variation. Therefore, for the comparison study, the monthly data from these five GNIP stations are used. Table 1 below shows the geographical and some climatic characteristics of the five stations as compared to that of Antananarivo. The mean annual temperature and the mean annual precipitation are the average values over the data collection period. 
Table 1. Geographical and climatic characteristics of the five GNIP stations for comparative study of isotope data in Precipitation (IAEA/World Meteorological Organization [WMO], 2021)

\begin{tabular}{lllllll}
\hline $\begin{array}{l}\text { GNIP Station } \\
\text { Name }\end{array}$ & $\begin{array}{l}\text { Data collection } \\
\text { Period }\end{array}$ & $\begin{array}{l}\text { Longitude } \\
(\text { decimal } \\
\text { degree) }\end{array}$ & $\begin{array}{l}\text { Latitude } \\
(\text { decimal } \\
\text { degree) }\end{array}$ & $\begin{array}{l}\text { Elevation } \\
(\mathrm{m} \text { a.s.l) }\end{array}$ & $\begin{array}{l}\text { Mean Annual } \\
\text { Temperature }\left({ }^{\circ} \mathrm{C}\right)\end{array}$ & $\begin{array}{l}\text { Mean Annual } \\
\text { Precipitation } \\
(\mathrm{mm})\end{array}$ \\
\hline $\begin{array}{l}\text { Antananarivo } \\
\text { Ivato }\end{array}$ & $1961-1975$ & 47.53 & -18.90 & 1295 & 17.79 & 1387 \\
$\begin{array}{l}\text { Antananarivo } \\
\text { Ankatso }\end{array}$ & $2009-2018$ & 47.55 & -18.91 & 1300 & 19.11 & 1209 \\
$\begin{array}{l}\text { Addis Ababa } \\
\text { Pretoria }\end{array}$ & $1961-2016$ & 38.73 & -8.98 & 2360 & 16.82 & 1160 \\
$\begin{array}{l}\text { Harare } \\
\text { Salta }\end{array}$ & $1961-2001$ & 28.23 & -25.75 & 1369 & 18.01 & 684 \\
Kunming & $1961-2003$ & 31.02 & -17.83 & 1471 & 18.44 & 831 \\
\hline
\end{tabular}

\subsubsection{Water Stable Isotopes ${ }^{18} \mathrm{O}$ and ${ }^{2} \mathrm{H}$}

Apart from temperature and precipitation amount, which play significant role on the isotope composition variability in precipitation (Wang et al., 2021), moisture source region condition also contributes.

Table 1 indicates that out of the six GNIP data stations, Antananarivo has the highest mean precipitation amount. The stable isotope composition of Antananarivo precipitation is plotted along with that of the five GNIP stations (Figure 5). Antananarivo has more depleted precipitations than the selected GNIP cities as figure 5 shows. Stable isotope depleted rainfalls are mostly associated with rainy period.

Figure 5a points out that the stable isotope composition of Addis Ababa rainfalls clearly shifts to the more enriched values. This is also expressed by the lower slope of the regression lines for Addis Ababa (Figure 5a). The high altitude and the low mean annual temperature of the Addis Ababa station would have led to stable isotopes depleted precipitations. The origin of the stable isotopes in meteoric waters in Ethiopia has been investigated (Kebede \& Travi, 2012). The authors concluded that there is no sign of enrichment as effect of evaporation, and the enriched $\delta^{18} \mathrm{O}$ and $\delta^{2} \mathrm{H}$ values in Addis Ababa rainfalls have long been recognized as a 'regional anomaly' (Kebede \& Travi, 2012). The Addis Ababa precipitations position on the isotope composition graph (Figure 5a) better represents low elevation station with high mean annual temperature, which are just the opposite of the station corresponding characteristics. Important source of moisture from the Congo Basin rainforest has been suggested to be the origin of the relatively high $\delta^{18} \mathrm{O}$ and $\delta^{2} \mathrm{H}$ values of Addis Ababa precipitation (Levin, Zipser, \& Cerling, 2009)

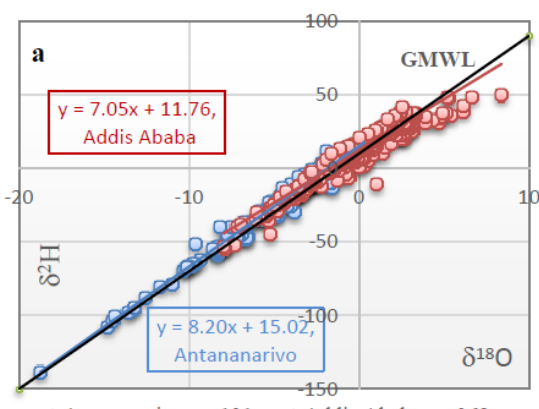

O Antananarivo, $\mathrm{n}=131 \quad \mathrm{O}$ Addis Ababa, $\mathrm{n}=362$

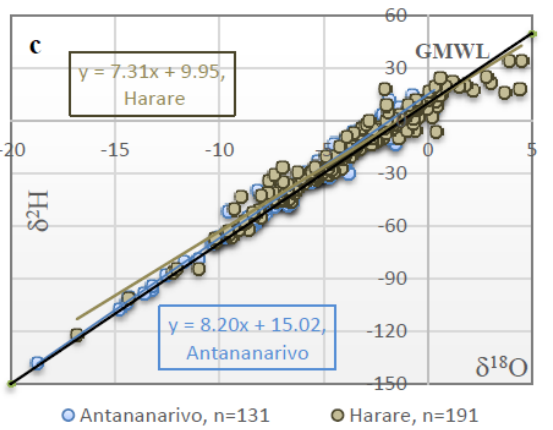

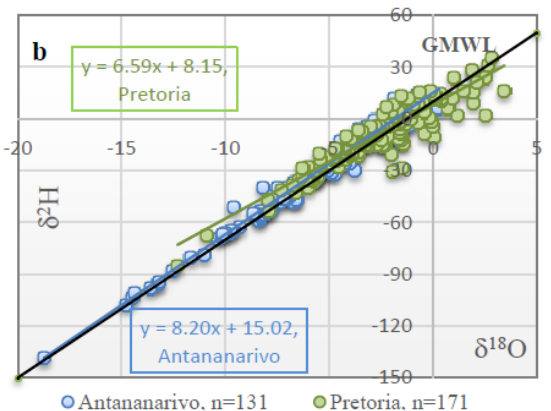

O Antananarivo, $\mathrm{n}=131 \quad$ OPretoria, $\mathrm{n}=171$

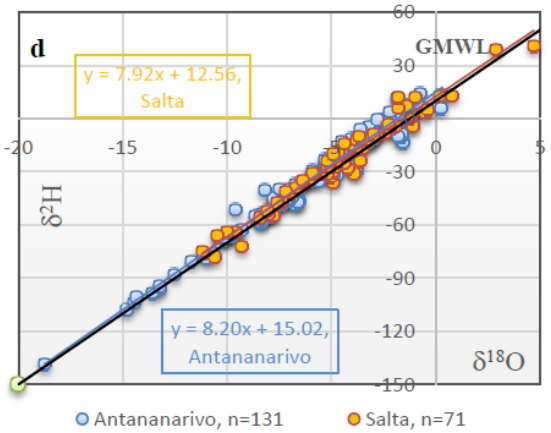




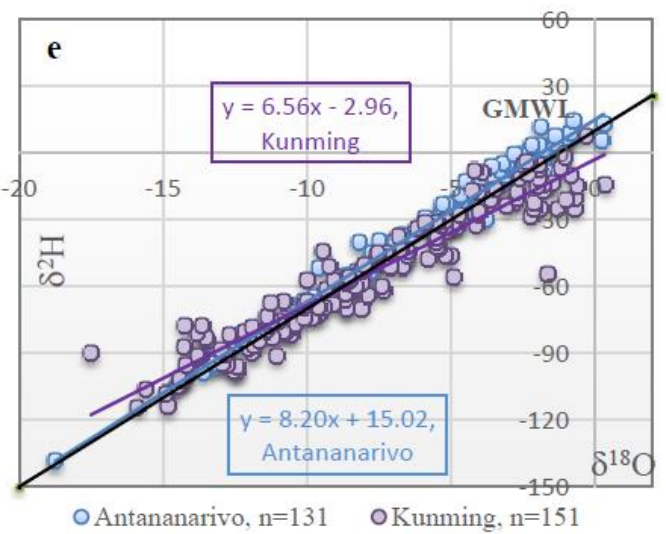

Figure 5. (a) Stable isotope compositions of Antananarivo and Addis Ababa rainfalls (b) Stable isotope compositions of Antananarivo and Pretoria rainfalls (c) Stable isotope compositions of Antananarivo Harare rainfalls (d) Stable isotope compositions of Antananarivo and Salta rainfalls (e) Stable isotope compositions of Antananarivo and Kunming rainfalls

Source: GNIP database

The isotopic composition of Pretoria and Antananarivo rainfalls mostly overlap, though the Pretoria precipitations are somehow more enriched in heavy isotopes than the Antananarivo precipitations (Figure 5b). This is well reflected by the slope value of the regression line (6.59) for Pretoria. The latter station records much lower annual precipitation amount, which would explain the more enriched precipitations. Indeed, in their study of Rainfall isotopic variability at the intersection between winter and summer rainfall regimes in coastal South Africa, Braun et al found that the stable isotopes show higher correlation with rainfall amount than with temperature due to the dominance of the amount effect in tropical atmospheric circulation systems (Braun, Bar-Matthews, Ayalon, \& Matthews, 2017). The isotopic composition of Harare and Antananarivo rainfalls almost perfectly overspread, with the isotope data falling nearly within the same range, except few more enriched values for Harare (Figure 5c). The seasonal change of the isotope composition of Harare essentially reflects that of Antananarivo Ivato (Rozanski, Araguas Araguas, \& Gonfiantini, 1996). As the intercept of the Harare regression line almost equals that of the GWML, variation of the relative humidity may contribute to the difference of the regression line equations of the two stations. Harare has low annual precipitation amount. In such a place, low relative humidity is related to lower slope of the regression line (Kendall \& Coplen, 2001). Salta has fewer GNIP recorded data and the data collection period is outside the range of the Antananarivo time period. Nevertheless, the slope values of the two stations are quite similar (Figure 5d), although the intercept is higher for Antananarivo. The $\delta^{18} \mathrm{O}$ variability in the south-central Andes (where Salta is located), is primarily regulated by precipitation amounts, which are controlled by the position and strength of the westerlies (Insel, Poulsen, Sturm, \& Ehlers, 2013). The isotope composition of precipitation in the East African regions, including Antananarivo is mainly governed by the displacement of the ITCZ (Rozanski et al., 1996). This difference would have led to the intercept variation.

Kunming and Antananarivo rainfalls almost lie within the same range (Figure 5e). However, the Kunming rainfalls show different pattern not only compared to that of Antananarivo but to that of the other four stations. Most of the precipitations from Antananarivo, Addis Ababa, Pretoria, Harare and Salta plot above the GMWL, while the majority of the Kunming rainfalls plots below the GMWL (Figure 5e). Precipitation samples plotting below the GMWL are indications of re-evaporation of raindrops during precipitation events (Banda, Rivett, Zavison, Kamtukule, \& Kalin, 2021). Small size raindrops of stratiform precipitation are inclined to kinetic fractionation under the cloud base, favoring exchange with surrounding air and re-evaporation ( $\mathrm{Li}$, Tang, \& Cui, 2021). The notable deviation from the GWML of the Kunming precipitations, with a regression line equation of $\delta^{2} \mathrm{H}=6.56 \delta^{18} \mathrm{O}-2.9$ would be from significant evaporative enrichment occurred during rainfall falling process (2021).

\subsubsection{Deuterium Excess}

Table 2 shows that the d-excess mean values for all six stations, except that of Kunming fall within the 10-20\% range, which is characteristic of wet season rains and typical to stations having high proportion of wet season precipitation (Banda et al., 2021). All six GNIP stations, including Antananarivo fall within this category. 
Sub-cloud evaporation of raindrops (that is re-evaporation of the falling raindrops) lead to d-excess value lower than $10 \%$ (Bershaw, 2018). The mean d-excess value $(8.30 \%$ ) of Kumming precipitations and their stable isotopes data highlight the same rainout process.

Except Kunming, Antananarivo has slightly higher mean and median d-excess values and differs essentially from the three east African stations by the minimum value. In these regional stations, including Antananarivo, the displacement of the ITCZ southward and northward control the rainfall regime. However, the rainfall period and frequency depend on the station location with respect to the ITCZ displacement (maximum, only southward, only northward, both southward and northward) (Rozanski et al., 1996). In summer, the regional circulation patterns are controlled by the easterly circulation, which brings moisture from the southwestern Indian ocean during the summer monsoon period (Rozanski et al., 1996). As Antananarivo is the closest to the major source of moisture, change of the meteorological factors along the moisture trajectory could explain the difference between neighboring stations (Addis Ababa, Pretoria, and Harare) on one hand and Antananarivo on the other hand.

Table 2. Statistical deuterium excess values of precipitations from the five GNIP stations (IAEA/World Meteorological Organization [WMO], 2021)

\begin{tabular}{lllllll}
\hline $\begin{array}{l}\text { GNIP Station } \\
\text { Name }\end{array}$ & $\begin{array}{l}\text { Number of } \\
\text { monthly data }\end{array}$ & $\begin{array}{l}\text { Mean d-excess } \\
\text { value }\left(\%{ }_{00}\right)\end{array}$ & $\begin{array}{l}\text { Standard } \\
\text { deviation }(\% 00)\end{array}$ & $\begin{array}{l}\text { Minimum } \\
\text { value }(\% 00)\end{array}$ & $\begin{array}{l}\text { Maximum } \\
\text { value }(\% 0)\end{array}$ & $\begin{array}{l}\text { Median } \\
(\% 00)\end{array}$ \\
\hline Antananarivo & 131 & 13.96 & 4.85 & -1.02 & 26.52 & 14.26 \\
Addis Ababa & 362 & 12.08 & 5.86 & -18.96 & 22.68 & 13.39 \\
Pretoria & 171 & 11.95 & 7.75 & -18.14 & 25.16 & 13.26 \\
Harare & 191 & 12.69 & 6.31 & -17.28 & 34.56 & 13.20 \\
Salta & 71 & 12.94 & 4.83 & 0.20 & 26.40 & 13.20 \\
Kunming & 151 & 8.30 & 11.06 & -41.18 & 50.18 & 8.68 \\
\hline
\end{tabular}

Deuterium excess in precipitation is function of several parameters such as sea surface temperature, relative humidity, wind speed at the site of evaporation (Uemura, Matsui,Yoshimura, Motoyama, \& Yoshida, 2008), humidity along the moisture trajectory and the occurrence of secondary evaporation in the sub-cloud (Clark \& Fritz, 1997). Deuterium excess in resultant precipitation increases by the addition of vapor from continental reservoirs along the moisture trajectory from the ocean (Guan et al., 2013). The occurrence of sub-cloud re-evaporation leads to a decrease in rainfall d-excess (Clark \& Fritz, 1997).

Deuterium excess is more sensitive to non-equilibrium phase change such as evaporation leading to kinetic fractionation processes (Masson-Delmotte et al., 2008). However, if the temperature varies during equilibrium fractionation (which occurs during condensation), the d-excess in the resultant precipitation may vary (Pfahl \& Wernli, 2008). Condensation taking place over a large vertical distance such as in convective event led to a d-excess gradient of $2 \%$ for a variation of $5^{\circ} \mathrm{C}$ in the equilibrium condensation temperature (Guan et al., 2013). Very low condensation temperature can lead to negative d-excess value (Dansgaard, 1964). For Addis Ababa, Pretoria and Harare, the most negative d-excess values refer to ones of the most enriched precipitations in stable isotopes, with monthly precipitation amount less than $35 \mathrm{~mm}$ and among the most monthly highest temperatures. During warm and dry months with minor rainfall amount, sub-cloud evaporation of the falling droplets leads to partially evaporated rain. This type of rain is characterized by relatively higher $\delta^{18} \mathrm{O}$ values and small to negative d-excess values (Gat et al., 2001).

Salta and Antananarivo have approximately the same minimal and maximal d-excess values, with almost the same standard deviations. This suggests that the d-excess values spread around the mean in the same way for the two stations. This further indicates the absence of other process such as sub-cloud evaporation or low condensation temperature which would have led to greater variability of the d-excess values of the precipitations from the two stations. As the Salta data period is outside the range of the Antananarivo data time interval, there would have not been any significant temporal variation of the d-excess governing factors.

\section{Conclusion}

The water stable isotope composition of precipitations at two stations in Antananarivo was compared to identify its spatial and temporal variation and understand the origin (s) of the dissimilarity. The datasets from the two stations have a tine gap of 34 years. The isotope data records $\left(\delta^{2} \mathrm{H}, \delta^{18} \mathrm{O}\right.$ and d-excess) from the two stations showed that the isotope composition of precipitation in Antananarivo varied over time. These changes are more perceptible during the two main annual seasons (winter and summer) as the air temperature and the precipitation 
amount during these seasons varied significantly over 34 years. The precipitations became more enriched in ${ }^{2} \mathrm{H}$ and ${ }^{18} \mathrm{O}$ within this time gap. For the inter-season months, no substantial disparity of the water isotope composition was observed. Over 34 years, if the air temperature in Antananarivo increased notably during the inter-season months, the precipitation amount remained consistent. This suggested that there was no substantial change in the conditions under which condensation occurs during these months. Furthermore, this would highlight the major role played by the precipitation amount in the isotope composition variation during the main seasons.

Therefore, this study also contributes to the knowledge of the temporal precipitation patterns variability in Antananarivo during the inter-season months.

Regarding the deuterium excess, the mean monthly values from both stations are higher than $10 \%$, and found to be indicating moisture recycling. In fact, higher $d$ values $(>10 \%)$ are characteristics of Indian Ocean $d$-values in tropical and sub-tropical regions. A temporal increase of the d-excess was also perceived and although this parameter is function of several factors, the rise could partly result from a much higher global evaporation flux of the surrounding ocean of Madagascar island, due to world climate warming.

Relating to spatial variation, the two stations are geographically close. The latitude and altitude effects, contributing factors to the change of isotope composition of precipitation, are negligeable for the Antananarivo precipitations under study.

The comparative study with data from regional and international GNIP stations showed variability between the isotope composition of precipitations from these stations and that of Antananarivo. At regional scale, different source of moisture, precipitation amount effect, and relative humidity would contribute to the isotope composition variability. Moreover, the station distance from the source of moisture would significantly contribute to the isotope composition variability of Antananarivo precipitation and that of its regional counterparts. At international scale, precipitation amount and secondary evaporation of raindrops during the rainfall falling process may be at the origins of the isotope composition variability in precipitation. With long-term and continuous isotope records in the future, the isotope composition variability in precipitation will help better understand the climate dynamics at local and regional scale.

\section{Acknowledgements}

The authors are thankful to the International Atomic Energy Agency through the Global Network of Isotopes in Precipitation, which coordinates shipment of rainfall samples and laboratory analyses of stable isotopes on yearly basis. The authors also acknowledge Randrianarivelo and Rasoarisoa Aimée for their kind collaboration in collecting rainfall samples from the Ankatso station.

\section{References}

Arivelo, T. A., \& Lin, Y-L. (2016). Climatology of Heavy Orographic Rainfall Induced by Tropical Cyclones over Madagascar: From Synoptic to Mesoscale Perspectives. Earth Science Research, 5(2), 132. https://doi.org/10.5539/esr.v5n2p132

Banda, L. C., Rivett, M. O., Zavison, A. S. K., Kamtukule, S., \& Kalin, R. M. (2021). National Stable Isotope Baseline for Precipitation in Malawi to Underpin Integrated Water Resources Management. Water, 13(14), 1927. https://doi.org/10.3390/w13141927

Bershaw, J. (2018). Controls on Deuterium Excess across Asia. Geosciences, 8, 257. https://doi.org/10.3390/geosciences8070257

Brand, W. A. (2011). New reporting guidelines for stable isotopes- an announcement for isotope users. Isotopes in Environmental and Health Studies, 47(4), 535-536. https://doi.org/10.1080/10256016.2011.645702

Braun, K., Bar-Matthews, M., Ayalon, A., \& Matthews, A. (2017). Rainfall isotopic variability at the intersection between winter and summer rainfall regimes in coastal South Africa. South African Journal of Geology, 120(3). https://doi.org/10.25131/gssajg.120.3.323

Clark, I. D., \& Fritz, P. (1997). Environmental Isotopes in Hydrogeology. Lewis Publishers. Boca Raton, Fla. pp. 348. https://doi.org/10.1201/9781482242911

Covell, M. A., Kent, R. K., Southall, A. W., Dresch, J., \& Deschamps, H. J. (2019). Madagascar. Encyclopedia Britannica. Retrieved from https://www.britannica.com/place/Madagascar/Climate

Craig, H. (1961). Isotopic variations in meteoric waters. Science, 133(3465), 1702-1703. https://doi.org/10.1126/science.133.3465.1702 
Dansgaard, W. (1964). Stable isotopes in precipitation. Tellus, 16(4), 436-468. https://doi.org/10.3402/tellusa.v16i4.8993

Froehlich, K., Gibson, J. J., \& Aggarwal, P. K. (2002). Deuterium excess in precipitation and its climatological significance. Proceedings of Study of Environmental Change using Isotope Techniques. International Atomic Energy Agency, Vienna (Austria). pp. 54-66. Retrieved from http://www-pub.iaea.org/MTCD/publications/PDF/CSP-13-P_web.pdf/

Fudeyasu, H., Ichiyanagi, K., Sugimoto, A., Yoshimura, K., Ueta, A., Yamanaka, M. D., \& Ozawa, K. (2008). Isotope ratios of precipitation and water vapor observed in Typhoon Shanshan. Journal of Geophysical Research: Atmospheres, 113(D12). https://doi.org/10.1029/2007JD009313

Gat, J. R., Mook, W. G., \& Meijer, H. A. J. (2001). Environmental Isotopes in the Hydrological cycle: Principles and Application. Volume 2: Atmospheric water. International Atomic Energy Agency and United Nations Educational, Scientific and Cultural Organization.

Govender, Y., Cuevas, E., Sternberg, L. D. S., \& Jury, M. R. (2013). Temporal Variation in Stable Isotopic Composition of Rainfall and Groundwater in a Tropical Dry Forest in the Northeastern Caribbean. Earth Interactions, 17(27), 1. https://doi.org/10.1175/2013EI000534.1

Guan, H., Zhang, X., Skrzypek, G., Sun, Z., \& Xu, X. (2013). Deuterium excess variations of rainfall events in a coastal area of South Australia and its relationship with synoptic weather system and atmospheric moisture sources. Journal of Geophysical Research: Atmospheres, 118(2), 1123-1138. https://doi.org/10.1002/jgrd.50137

Hughes, C. E., \& Crawford, J. (2012). A new precipitation weighted method for determining the meteoric water line for hydrological applications demonstrated using Australian and global GNIP data. Journal of Hydrology, 464-465, 344-351. https://doi.org/10.1016/j.jhydrol.2012.07.029

IAEA/WMO. (2021). Global Network of Isotopes in Precipitation. The GNIP Database. Retrieved from https://nucleus.iaea.org/wiser

Insel, N., Poulsen, C. J., Sturm, C., \& Ehlers, T. A. (2013). Climate controls on Andean precipitation $\delta 180$ interannual variability. Journal of Geophysical Research: Atmosphere, 118, 9721-9742. https://doi.org/10.1002/jgrd.50619

International Atomic Energy Agency. (2014). AIEA/GNIP Precipitation Sampling Guide. Booklet. Retrieved from http://www-naweb.iaea.org/napc/ih/documents/other/gnip_manual_v2.02_en_hq.pdf

Jackisch, D., Yeo, B. X., Switzer, A. D., He, S., Cantarero, D. L. M., Siringan, F. P., \& Goodkin, N. F. (2020). Precipitation stable isotopic signatures of tropical cyclones in Metropolitan Manila, Philippines shows significant negative isotopic excursions, Nat. Hazards Earth Syst. Sci. Discuss. https://doi.org/10.5194/nhess-2019-352

Jury, M. R. (2003). The climate of Madagascar. In S. M. Goodman \& J. P. Benstead (Eds.), The Natural History of Madagascar. University of Chicago Press book.

Kebede, S., \& Travi, Y. (2012). Origin of the $\delta^{18} \mathrm{O}$ and $\delta^{2} \mathrm{H}$ composition of meteoric waters in Ethiopia. Quaternary International, 257, 4-12. https://doi.org/10.1016/j.quaint.2011.09.032

Kendall, C., \& Coplen, T. B. (2001). Distribution of oxygen-18 and deuterium in river waters across the United States. Hydrological Processes, 15(7), 1363-1393. https://doi.org/10.1002/hyp.217

Kendall, C., \& McDonnell, J. J. (1998). Isotope Tracers in Catchment Hydrology. Elsevier Science B.V., Amsterdam. pp. 51-86. https://doi.org/10.1016/B978-0-444-81546-0.50009-4

Kottek, M., Grieser, J., Beck, C., Rudolf, B., \& Rubel, F. (2006). World Map of the Köppen-Geiger climate classification Updated. Meteorologische Zeitschrift, 15(3), 259-263. https://doi.org/10.1127/0941-2948/2006/0130

Kumar, A., Tiwari, S. K., Verma, A., \& Gupta, A. K. (2018). Tracing isotopic signatures ( $\delta \mathrm{D}$ and $18 \mathrm{O})$ in precipitation and glacier melt over Chorabari Glacier-Hydroclimatic inferences for the Upper Ganga Basin (UGB), Garhwal Himalaya. Journal of Hydrology: Regional Studies, 15, 68-89.

https://doi.org/10.1016/j.ejrh.2017.11.009

Lawrence, R. J., \& Gedzelman, D. S. (1996). Low stable isotope ratios of tropical cyclone rains. Geophysical Research Letters, 23(5), 527-530. https://doi.org/10.1029/96GL00425 
Lawrence, J. R., Gedzelman, S. D., Zhang, X., \& Arnold, R. (1998). Stable isotope ratios of rain and vapor in 1995 hurricanes. Journal of Geophysical Research: Atmospheres, 103(D10), 11381-11400. https://doi.org/10.1029/97JD03627

Levin, N. E., Zipser, E. J., \& Cerling, T. E. (2009). Isotopic composition of waters from Ethiopia and Kenya: Insights into moisture sources for eastern Africa. Journal of Geophysical Research, 114(D23306). https://doi.org/10.1029/2009JD012166

Li, X., Tang, C., \& Cui, J. (2021). Intra-Event Isotopic Changes in Water Vapor and Precipitation in South China. Water, 13, 940. https://doi.org/10.3390/w13070940

Masson-Delmotte, V., Hou, S., Ekayrin, A., J., Aristarain, A., Bernardo, R. T., ... White, J. W. C. (2008). A review of Antarctic surface snow isotopic composition: Observations, atmospheric circulation, and isotopic modelling. Journal of Climate, 21(13), 3359-3387. https://doi.org/10.1175/2007JCLI2139.1

Mavume, A. F., Rydberg, L., Rouault, M., \& Lutjeharms, J. R. E. (2009). Climatology and Landfall of Tropical Cyclones in the South- West Indian Ocean. Western Indian Ocean J. Mar. Sci., 8(1), 15-36. https://doi.org/10.4314/wiojms.v8i1.56672

Mazor, E. (2004). Chemical and Isotopic Groundwater Hydrology (3rd ed.). Marcel Dekker. Inc. BOOK. https://doi.org/10.1201/9780203912959

Metz, H. C. (1995). Indian Ocean: five island countries (3rd ed.). Federal Research Division, Library of Congress.

Müller, T., Friesen, J., Weise, S. M., Al Abri, O., Bait Said, A. B. A., \& Michelsen, N. (2020). Stable isotope composition of Cyclone Mekunu rainfall, Southern Oman. Water Resources Research, 56, e2020WR027644. https://doi.org/10.1029/2020WR027644

Peel, M. C., Finlayson, B. L., \&. McMahon, T. A. (2007). Updated world map of the Koppen- Geiger climate classification. Hydrol. Earth Syst. Sci., 11, 1633-1644, 2007. https://doi.org/10.5194/hess-11-1633-2007

Penna, D., Stenni, B., Šanda, M., Wrede, S., Bogaard, T. A., Michelini, M., ... Wassenaar, L. I. (2012). Technical Note: Evaluation of between-sample memory effects in the analysis of $\delta^{2} \mathrm{H}$ and $\delta^{18} \mathrm{O}$ of water samples measured by laser spectroscopes. Hydrol. Earth Syst. Sci., 16, 3925-3933. https://doi.org/10.5194/hess-16-3925-2012

Pfahl, S., \& Wernli, H. (2008). Air parcel trajectory analysis of stable isotopes in water vapor in the eastern Mediterranean. Journal of Geophysical Research: Atmospheres, 113(D20). https://doi.org/10.1029/2008JD009839

Pinti, D. (2011). Delta, Isotopic. In M. Gargaud et al. (Eds.), Encyclopedia of Astrobiology. Springer, Berlin, Heidelberg. https://doi.org/10.1007/978-3-642-11274-4_406

Putman, A. L., \& Bowen, G. J. (2019). Technical Note: A global database of the stable isotopic ratios of meteoric and terrestrial waters. Hydrol. Earth Syst. Sci., 23, 4389-4396. https://doi.org/10.5194/hess-23-4389-2019

Rambinintsoa, T., Rakoto, D. S., Rambinintsoa, F., Raveloalison, H., \& Andrianaivo, L. (2019). Findings and Diagnoses on Urbanizing Antananarivo City. Mada-Hary, 8, 63-72. Retrieved from http://madarevues.recherches.gov.mg/IMG/pdf/hary8_8_.pdf

Ren, W., Yao, T., \& Xie, S. (2016). Water stable isotopes in the Yarlungzangbo headwater region and its vicinity of the southwestern Tibetan Plateau. Tellus B: Chemical and Physical Meteorology, 68(1), 30397. https://doi.org/10.3402/tellusb.v68.30397

Roth, M. (2007). Review of urban climate research in (sub) tropical regions. International Journal of Climatology, 27, 1859-1873. https://doi.org/10.1002/joc.1591

Rozanski, K., Araguas Araguas, L., \& Gonfiantini, R. (1996). Isotope patterns of precipitation in the East African region. In T. L. Johnson \& E. Obada (Eds.), The Limnology, Climatology and Paleoclimatology of the East African Lakes. Gordon and Breach Publishers.

Sánchez-Murillo, R., Esquivel-Hernández, G., Welsh, K., Brooks, E. S., Boll, J., Alfaro-Solís, R., \& Valdés-González, J. (2013). Spatial and Temporal Variation of Stable Isotopes in Precipitation across Costa Rica: An Analysis of Historic GNIP Records. Journal of Modern Hydrology, 3, 226-240. https://doi.org/10.4236/ojmh.2013.34027

Singh, B. P. (2017). Original isotopic composition of water in precipitation by different methods. Applied Water 
Science, 7, 3385-3390. https://doi.org/10.1007/s13201-016-0500-6

Sodemann, H., Schwierz, C., \& Wernli, H. (2008). Interannual variability of Greenland winter precipitation sources: Lagrangian moisture diagnostic and North Atlantic Oscillation influence. Journal of Geophysical Research: Atmospheres, 113(D3). https://doi.org/10.1029/2007JD008503

Stern, L. A., \& Blisniuk, P. M. (2002). Stable isotope composition of precipitation across the southern Patagonian Andes. Journal of Geophysical Research, 107(D23), 3667. https://doi.org/10.1029/2002JD002509

Tadross, M., Randriamarolaza, L., Rabefitia, Z., \& Zheng, K. Y. (2008). Climate change in Madagascar; recent past and future. Report. Washington, DC: World Bank. pp. 18. Retrieved from https://www.researchgate.net/publication/266244734_Climate_Change_in_Madagascar_Recent_Past_and_ Future

Tappa, D. J., Kohn, M. J., Mcnamara, J. P., \& Flores, A. N. (2016). Isotopic composition of precipitation in a topographically steep, seasonally snow-dominated watershed and implications of variations from the Global Meteoric Water Line: Precipitation isotopes in a steep, seasonally snow-dominated watershed. Hydrological Processes, 30(24), 4582-4592. https://doi.org/10.1002/hyp.10940

Tyler, B. C. (2011). Guidelines and recommended terms for expression of stable-isotope-ratio and gas-ratio measurement results. Rapid Commun. Mass Spectrom, 25, 2538-2560. https://doi.org/10.1002/rcm.5129

Uemura, R., Matsui, Y., Yoshimura, K., Motoyama, H., \& Yoshida, N. (2008). Evidence of deuterium excess in water vapor as an indicator ofocean surface conditions. Journal of Geophysical Research, 113(D19114). https://doi.org/10.1029/2008JD010209

United States Agency for International Development. (2016). Climate Change Risk Profile-Madagascar. Climate Change Adaptation, Thought Leadership and Assessments (ATLAS) Fact Sheet. Task Order No. AID-OAA-I-14-00013.

Wachsberger, J-M. (2009). The poor neighborhoods in Antananarivo. Poverty trap or support for individuals? (in French). Presses de Sciences Po, Autrepart, 3(51), 117-137. https://doi.org/10.3917/autr.051.0117

Wang, J., Li, W., Wang, Y., Zhang, J., \& Xiao, S. (2021). Characteristics of Stable Isotopes in Precipitation and Their Moisture Sources in the Guanling Region, Guizhou Province. Research article. Hindawi Journal of Chemistry, 2021, 12. https://doi.org/10.1155/2021/5569793

Weinkle, J., Maue, R., \& Plielke, R. Jr. (2012). Historical Global Tropical Cyclone Landfalls. Journal of Climate, 25, 4729-4735. https://doi.org/10.1175/JCLI-D-11-00719.1

World Bank Group. (2011). Vulnerability, Risk Reduction, and Adaptation to Climate Change: Madagascar. Climate Risk and Adaptation Country Profile.

World Bank Group. (2020). Climate Change Knowledge Portal. Retrieved from https://climateknowledgeportal.worldbank.org/country/madagascar

Wu, H., Zhang, X., Xiaoyan, L., Li, G., \& Huang, Y. (2015). Seasonal variations of deuterium and oxygen-18 isotopes and their response to moisture source for precipitation events in the subtropical monsoon region. Hydrological Processes, 29(1). https://doi.org/10.1002/hyp.10132

Wu, H., Fu, C., Zhang, C., Wei, Z., \& Zhang, X. (2021). Stable Isotopic variability of Daily Precipitation from Yungui Plateau of Southwest China: Insights from Moisture Source and Rainout Effect. Research square. https://doi.org/10.21203/rs.3.rs-602537/v1

Yabusaki, S., Tase, N., \& Tsujimora, M. (2006). Temporal variation of stable isotopes in precipitation at Tsukuba City. Tsukuba Geoenvironmental Sciences, 2, 31-35.

\section{Copyrights}

Copyright for this article is retained by the author(s), with first publication rights granted to the journal.

This is an open-access article distributed under the terms and conditions of the Creative Commons Attribution license (http://creativecommons.org/licenses/by/4.0/). 